\title{
INDUSTRIALIZAÇÃO NO PARAGUAI: PERSPECTIVAS A PARTIR DA LEI DE MAQUILA
}

\author{
Cláudia Heloiza Conte ${ }^{1}$
}

Resumo: $O$ objetivo desse trabalho é compreender 0 atual processo de industrialização do Paraguai através da instalação da lei de maquila. Trata-se de uma atividade recente, que busca alterar a dinâmica social e econômica do país, historicamente baseada nas atividades primárias e terceárias. Buscou-se o entendimento da formação socioespacial do Paraguai através da análise da gênese e evolução de suas atividades produtivas, para em seguida abordar os elementos integrantes da lei de maquila, sua efetivação e seus resultados iniciais. Verificou-se que, apesar dos investimentos em divulgação e do crescimento no número de indústrias instaladas nos últimos anos, a atividade ainda não foi capaz de alterar a realidade social e econômica do país.

Palavras-Chave: Industrialização, Lei de Maquila, Paraguai.

\section{INDUSTRIALIZATION IN PARAGUAY: PERPECTIVES FROM MAQUILA LAW}

Abstract: The objective of this paper is understand the current process of industrialization in Paraguay through the installation of maquila law. It's a recent activity that seeks to change de social and economic dynamics of conuntry, historically based on primary and thirdy activities. The understanding of Paraguay social spatial formation was sought through the analysis of the genesis and evolution of it's productive activities, in order to approach the constituent elements of the maquila law, it's effectiveness and initial results. It was verified that, despite the investments in dissimination and the growth in the number of industries installed in recent years, the activity has not yet benn able to change the social and economic reality of the country.

Key-words: Industrialization, Maquila Law, Paraguay.

\section{INTRODUÇÃO}

O Paraguai conta com uma população de 6 milhões e 800 mil habitantes, formada por um grande número de jovens (45\%) e com uma considerável população rural (cerca de 40\%) (DEEGEC, 2014). Apesar da crescente migração para a cidade, o país destacou-se nos últimos anos por relativa recuperação e crescimento do PIB, especialmente a partir de 2003 , com uma taxa de $4,5 \%$ anual. Isso está relacionado com o crescimento da produção e exportação de grãos e carne bovina² (MOLINIER,

\footnotetext{
${ }^{1}$ Professora da Universidade Estadual de Mato Grosso do Sul - UEMS. Doutora em Geografia pela Universidade Estadual de Londrina - UEL. Email: claudiaheloiza@ yahoo.com.br

${ }^{2}$ Aproximadamente $3 / 4$ do total das exportações paraguaias de carne bovina são realizadas por frigoríficos de capital brasileiro. A participação é ainda maior no caso dos envios de carne direcionados ao Brasil, seu terceiro destino, atrás da Rússia e do Chile.
} 
2015), no entanto, esse crescimento não foi capaz de criar empregos e alterar a estrutura social desigual.

Soma-se a isso o fato de que, o Paraguai caracteriza-se por atividades econômicas que são desenvolvidas majoritariamente na região oriental ${ }^{3}$ do país, onde encontram-se as maiores cidades ${ }^{4}$, as poucas indústrias, as atividades comerciais e $97,5 \%$ da população. Sua base econômica é definida pelo setor agropecuário e pelo comércio, os quais foram se consolidando, da mesma forma como a ausência de um processo de industrialização. Para Lamberti (2011), a ausência de alternativas, decorrente da falta de uma política econômica voltada para a criação de outras atividades industriais, com uso intensivo de mão-de-obra, está no cerne do elevado número de pessoas ocupadas na triangulação comercial, em serviços bancários e financeiros, assim como no subemprego urbano.

Com um histórico de reduzida presença de indústrias em seu território, uma nova dinâmica, baseada na lei de maquila do México, foi instaurada no Paraguai no final da década de 1990, com a criação da lei de Maquila do Paraguai, a qual permite, desde 2000, que indústrias estrangeiras instalem-se no país com uma tributação única de $1 \%$ sobre o valor agregado, além da importação livre de impostos e baixo custo de mão-de-obra, com a contrapartida de que os produtos industrializados sejam exportados para o país de origem dentro de dois anos.

Para compreender como este recente processo está alterando a dinâmica econômica e social do Paraguai, o trabalho está dividido em três partes. Na primeira será realizada uma discussão acerca do processo de formação social e do desenvolvimento das atividades produtivas no Paraguai, para em seguida analisar a gênese e o desenvolvimento da lei de maquila no país e seus desdobramentos na dinâmica atual do mesmo. Por último serão traçadas algumas considerações sobre esse processo.

\section{FORMAÇÃO E DESENVOLVIMENTO SOCIAL E ECONÔMICO DO PARAGUAI}

O Paraguai tornou-se independente após conflito com a Argentina, que buscava manter o Vice-Reinado do Prata, unido em 1811. Com a negativa por parte do Paraguai, Buenos Aires criou entraves para o comércio externo paraguaio, pois era através do porto de Buenos Aires que ocorriam as transações. Com o intuito de promover o desenvolvimento do país, agora isolado, o governo de Francia confiscou as terras dos grandes proprietários e passou a controlar a produção ali realizada. "[...] del $100 \%$ en el Chaco y del $98,4 \%$ en la Región Oriental. De las 16.590 leguas cuadradas en que era estimada entonces la superficie del territorio nacional, solamente 261 leguas cuadradas eran del dominio privado de sus habitantes" (PASTORE, 1972, p. 178).

Nesta perspectiva, Francia inaugurou o que seria denominado de desenvolvimento autônomo, fechando as fronteiras e fomentando a agricultura e a pecuária nas terras estatais. Com isso, ocorreu a reordenação das estruturas sócio econômicas da sociedade paraguaia, distanciando-se da matriz colonial (BOURSCHEID, 2014).

\footnotetext{
3 A porção oriental corresponde a $159.827 \mathrm{~km}^{2}$ e é formada por planícies, bosques e ampla rede fluvial. A porção ocidental, conhecida como Chaco, corresponde a $246.925 \mathrm{~km}^{2}$ e caracteriza-se por uma grande planície, escassez de água e clima semi desértico (LAMBERTI, 2011).

${ }^{4} \mathrm{O}$ país está dividido em 17 departamentos, além de distritos e aproximadamente 200 cidades.
} 
Com uma visão mais progressista, Carlos López sucedeu Francia e assumiu o poder em 1844. Este passou a negociar com alguns países, além de tentar aproximarse dos vizinhos da Bacia do Prata. Essa aproximação foi bem recebida pelo governo brasileiro, que no mesmo ano tornou-se o primeiro país a reconhecer a independência do Paraguai (SALES, 2004). Nesse momento a economia paraguaia apresentava considerável crescimento, com a fundação, em 1850, de uma fábrica de canhões e armamentos, a siderurgia nacional. Tanto a fábrica como todos os serviços básicos encontravam-se sob controle do Estado (ODDONE, 2008).

No período do governo de Carlos López (1844-1862) ocorreram grandes transformações sociais e econômicas em âmbito mundial, como a expansão das relações internacionais, a consolidação da industrialização inglesa e a expansão das relações sociais capitalistas. Neste sentido, o Paraguai aprofundou suas relações comerciais com a Inglaterra e instalou algumas indústrias no país. Londres era responsável pela maior parte dos empréstimos realizados aos países da América do Sul e pela maior parte do capital investido na infraestrutura, agricultura e mineração. Além disso, a Inglaterra era um dos mais importantes mercados para matérias-primas e produtos agrícolas. Desta forma, o estabelecimento comercial dos britânicos na América do Sul durante o século XIX, ocorria especialmente para importar e distribuir artigos têxteis, utensílios de ferro, porcelana, vidro, mobília, etc. Lênin (2011, p.180) caracteriza esse processo:

O desenvolvimento da troca, tanto no interior como, em especial, no campo internacional, é um traço distintivo e característico do capitalismo. O desenvolvimento desigual, por saltos, das diferentes empresas e ramos da indústria e dos diferentes países é inevitável sob o capitalismo. A Inglaterra foi a primeira que se transformou em país capitalista, e em meados do século XIX, ao implantar o livre câmbio, pretendeu ser a "oficina de todo o mundo", o fornecedor de artigos manufaturados para todos os países, os quais deviam fornecer-Ihe, em contrapartida, matérias-primas.

Foi na década de 1850, após a Argentina autorizar a livre navegação no rio Paraná, que o comércio exterior do Paraguai começou a desenvolver-se. Berthell (1995) evidencia que, as exportações multiplicaram-se duas vezes na segunda metade de 1850, sendo que neste período o governo do Paraguai controlava metade do território nacional, exercendo o monopólio sobre o cultivo e exportação de ervamate, couro e madeira. Entretanto, o principal obstáculo para a efetiva abertura da economia paraguaia era a dificuldade em realizar exportações, pois os produtos deveriam ir até Buenos Aires e a viagem até lá durava aproximadamente três meses.

Com a morte de Carlos López em 1862, Solano López assumiu o poder e deu continuidade à política interna de seus dois antecedentes. De acordo com Sales (2004), o novo presidente, influenciado pelo ministério que ocupava, passou a destinar grande parte das verbas do governo para a preparação de um exército forte, coeso e bem armado; buscou também aumentar a participação do Paraguai nas decisões e conflitos referentes à Bacia do Prata.

Neste contexto deve-se frisar que, durante a primeira metade do século XIX a história do Uruguai foi marcada pela instabilidade e alternância dos partidos Blanco e Colorado no governo. Essa instabilidade foi responsável pelo início de uma guerra civil entre os dois partidos, que perdurou de 1830 até o final da década de 1850. Com a ascensão do partido Blanco ao poder em 1861, a conjuntura política e social do Uruguai tornou-se instável, o governo criou impostos que atingiram produtores rurais 
do Rio Grande do Sul que possuíam propriedades no Uruguai, além de romper o Tratado de Comércio e Navegação com o Império brasileiro.

No mesmo contexto, a Argentina estabelecia medidas para unificação do Estado através de Bartolomeu Mitre, combatendo os federalistas da oposição. Os governos do Brasil e Argentina, através de apoio ao partido de oposição à Berro, o Colorado, visualizaram a oportunidade de conseguir seus objetivos junto ao Uruguai. Nesta perspectiva, Berro buscou apoio com os federalistas argentinos e com o governo paraguaio para combater os avanços colorados. Embora nunca tenha assinado um acordo, o apoio paraguaio veio de forma declarada. Com a intervenção brasileira e argentina no Uruguai, Solano López rompe suas relações e declara guerra aos dois países (SALES, 2004).

Contra as pretensões do governo paraguaio, Brasil, Argentina e Uruguai firmam o acordo militar conhecido como Tríplice Aliança e juntos enfrentam o Paraguai. Esse foi apenas o início de uma guerra que tomaria grandes proporções e que se estendeu até 1870, constituindo-se no maior conflito armado da América do $\mathrm{Sul}^{5}$. Com a derrota do Paraguai na guerra, o Estado autônomo paraguaio deu lugar a um Estado liberal. Essa mudança ocorreu especialmente pela importante diminuição demográfica do país, que perdeu $70 \%$ de sua população na guerra.

Los autores analizan los datos censales y realizan estimaciones sobre posibles omisiones, así como consideraciones comparativas con el Censo de 1846. En definitiva, el Censo de 1870 contabiliza 116.351 habitantes de los cuales $29 \%$ eran hombres y $71 \%$ mujeres. $\mathrm{Si}$ tomamos en cuenta que la tasa de crecimiento de la población se encontraba en ascenso en 1846 y que la tendencia del casi medio siglo transcurrido previamente a ese año orillaba el 3\% anual acumulativo, bien puede afirmarse que, de no haber mediado una guerra de exterminio como la de la Triple Alianza, con esa tasa la población paraguaya habría duplicado su tamaño entre 1846 y 1870, llegando a superar los 460.000 habitantes Odonne (ODONNE, 2011, p.3).

As perdas resultantes da guerra não se restringiram as demográficas, pois cerca de 160 mil quilômetros do território paraguaio foram anexados aos territórios do Brasil e da Argentina, como parte do Tratado da Tríplice Aliança. As terras que anteriormente pertenciam ao Estado, foram compradas por poucos proprietários estrangeiros, que instauraram latifúndios, na maior parte dos casos improdutivos ou extrativos $^{6}$, impedindo assim o desenvolvimento de uma classe agroprodutora paraguaia. Para Quintin (2003), esse foi o início da rápida estruturação da grande propriedade no Paraguai. Soma-se a isso a crescente dependência econômica do Brasil e da Argentina, a perda de sua soberania nacional, bem como 0 desaparecimento de uma industrialização ainda incipiente, mas que surgia estimulada pelos processos conjunturais nacionais e internacionais daquele período.

Os anos de 1870 a 1936 compreendem o fim do conflito bélico que esgotou as reservas econômicas; o aparato produtivo foi mantido apenas ao nível de subsistência e a incipiente indústria se converteu às necessidades de sobrevivência. O Estado e a sociedade se debilitaram a ponto de ser necessária sua reconstrução em todos os

\footnotetext{
${ }^{5}$ Para maior aprofundamento a respeito da Guerra do Paraguai ler BANDEIRA (1985).

${ }^{6}$ A privatização das terras a partir de 1885 foi em grande parte destinada a empresas argentinas e brasileiras, como Carlos Casado e industrial Paraguaya e Mate Laranjeira (CANESE, 2008). Todas as estatais foram privatizadas até 1936.
} 
aspectos. Para captar recursos foi vendida a maior parte das terras fiscais inclusive a proprietários que nunca chegaram a residir no país (LAMBERTI, 2011, p.68).

As principais características desse período estão ligadas a fundação de uma estrutura política institucional liberal, reconstrução da propriedade com base nas relações privadas, definição das bases de uma economia exportadora dominada pelo capital anglo-argentino e o latifúndio. A instabilidade política advinda da guerra é compreendida ao verificar que, entre o governo de Solano López e de Stroessner, o Paraguai teve um presidente a cada 23 meses, sendo que na vigência de 44 deles, 24 foram retirados do poder (LAMBERTI, 2011).

$\mathrm{Na}$ segunda metade do século XX verifica-se a legitimação de um Estado que inseriu o setor agroexportador no contexto de uma economia aberta. Deste modo, a partir de 1950 a dinâmica do país esteve atrelada a uma lógica agroexportadora com suas fronteiras abertas e com espaço para fluxos de intercâmbios comerciais e financeiros. A década de 1960 teve um índice de crescimento anual do PIB em torno de $4,2 \%$. Neste momento, o capital estrangeiro, diante da retração das exportações de madeira e erva-mate, cederam ao Estado suas grandes propriedades a um baixo preço, em troca de outros bens imobiliários. Os dados de 1956 mostram que, aproximadamente $74 \%$ da terra do país eram grandes propriedades. Neste período $20 \%$ da população vivia nas cidades (LAMBERTI, 2011).

O primeiro censo industrial do país foi realizado em 1955 e identificou que o dinamismo das exportações estava baseado no processamento de produtos agropecuários. Dos 2.722 estabelecimentos e 34.449 empregados contabilizados, $70 \%$ eram dos setores de alimentos e bebidas, têxteis e produtos químicos, gerando $80 \%$ do valor da produção industrial.

De um modo geral, durante os anos de 1950, os capitais estrangeiros no Paraguai continuaram sendo pouco significativos, mas essa tendência seria modificada na década posterior em especial porque vários bancos estrangeiros se instalaram no país a partir de então. Ou seja, durante esse período o Paraguai teve acesso ao capital estrangeiro na forma de créditos e assistência econômica, sendo que boa parte foi canalizada através do Estado e destinaram-se principalmente para a criação, ampliação e modernização da infraestrutura de transporte e comunicações. O resultado desses investimentos materializou-se na integração interna da economia paraguaia inclusive com a economia regional e com o Brasil (LAMBERTI, 2011, p.98).

Na primeira década de governo Stroessner, o Fundo Monetário Internacional FMI, enviou uma comissão para elaborar um plano de reformas, que transformou-se no Plano de Estabilização. Estavam previstas as seguintes etapas: 1) restrição ao crédito e manutenção das reservas monetárias; 2) alteração do sistema cambial para fomentar as exportações; 3) melhorias internas: construção de novas estradas, escolas, instalações portuárias, saneamento, eletrificação para estimular a indústria, o comércio e a força de trabalho; 4) reforma do sistema de impostos, em especial a abolição dos altos impostos à exportação (LAMBERTI, 2011).

Enquanto os industriais mostravam-se insatisfeitos com a política monetária restritiva, a atração de capital estrangeiro crescia através de incentivos aos investidores estrangeiros: exceção de impostos aduaneiros e fácil acesso as reservas cambiais do Banco Central, bem como a redução de impostos a fim de facilitar a 
entrada de novas indústrias, especialmente aquelas de produtos para exportação. Soma-se aos incentivos, a construção das hidroelétricas, que resolveria a problemática da falta de energia, um importante obstáculo para a industrialização. As empresas brasileiras, argentinas, norte-americanas e italianas tinham como destino as áreas de processamento de madeira, celulose e papel, de refino de açucar e têxteis, processamento de alimentos e construção.

De acordo com orientação do FMI, o governo estimulava a iniciativa privada através da criação de condições necessárias. Mais da metade dos fundos públicos teve como destino a melhoria do transporte e da comunicação, além da modernização da frota fluvial, construção de aeroporto e compra de aviões de carga e de passageiros pelas três empresas do governo.

Además, como en muchos otros países latinoamericanos, las
debilidades - en algunos casos la carencia absoluta - de instituciones
democráticas de la sociedad civil, han empeorado la desigualdad
económica y social, y han creado, como consecuencia, situaciones
peligrosas de inestabilidad política. Esta frágil conformación de las
instituciones internas - integradas por estructuras y relaciones entre
agentes económicos - ha afectado adversamente no solo a la
distribución de ingresos sino también al proprio crecimiento de la
producción (BORDA, 1994, p. 02).

Em relação a necessidade de combate à inflação e a especulação, a opção foi pela regulação dos mercados financeiro, trabalhista e agrícola. Outro elemento a ser superado pelo governo paraguaio era a dependência em relação a Argentina, que era o principal sócio comercial, como opção de escoamento da produção. Neste sentido, a aproximação comercial e diplomática com o Brasil mostrou-se uma alternativa para se chegar ao porto de Paranaguá.

A década de 1970 destacou-se pelo crescimento, com taxa anual média de 8\%, que por sua vez atingiu 11\% entre 1977 e 1980. A agricultura (algodão e soja) e a construção civil foram os setores mais dinâmicos, haja vista a valorização internacional para esses produtos, além é claro, das obras da Usina de Itaipu. $\mathrm{O}$ resultado foi o ingresso de considerável volume de recursos financeiros, que permitiu a ampliação do mercado interno de bens e serviços.

César (2016), inserido nesta discussão evidencia que, a construção de Itaipu significou um importante ingresso de capitais na economia do Paraguai, provocando, inclusive, um incipiente processo de industrialização vinculado ao aumento do gasto público. No entanto, o crescimento da triangulação comercial, no final do governo Stroessner, inibiu o desenvolvimento da mesma. Soma-se a isso o fato de que, a construção da usina não foi acompanhada da ampliação de infraestrutura de distribuição da energia elétrica, ao contrário, o Paraguai tornou-se o principal exportador de energia hidroelétrica do mundo.

El Paraguay no siguió en las décadas de 1960 y de 1970 el modelo de sustitución de importaciones adoptado por la mayoría de los países latinoamericanos, ni desarrolló, por la misma razón, políticas altamente proteccionistas. Estuvo, así, más expuesto que otros países de la región a la competencia internacional. Además, la permeabilidad de sus fronteras y su debilidad institucional para contener los flujos del contrabando de importación desde el Brasil y la Argentina le convirtieron en la economía más abierta del Mercosur. Sin embargo, ese grado de apertura y de baja protección no hizo que su producción 
industrial ganara competitividad internacional. De hecho, el Paraguay ha quedado detenido en un estadio de muy bajo desarrollo industrial debido al modelo económico que privilegió la exportación de materias primas agropecuarias; a la limitación estructural de la estrechez del mercado interno (superada luego formal y relativamente por la constitución del Mercosur); y también, probablemente, a la dificultad de las incipientes industrias para desenvolverse en el ambiente de la alta intensidad del contrabando, en ausencia de políticas genuinas de apoyo a la actividad fabril (BORDA, 1994, p. 15).

Sobre a manufatura durante este período, destaque para a influência dos investimentos estrangeiros diretos, constituindo um dos aspectos do novo momento econômico que se iniciava. A indústria foi um dos setores onde ocorreu esse tipo de investimento, em especial as agroindústrias. Para se ter noção, em 1985 haviam 199 empresas com capital estrangeiro, sendo que as indústrias de alimentos e madeira representavam $22 \%$ delas, produtos químicos e metálicos $6,5 \%$ cada, bebidas $5,5 \%$ e materias de construção 5\%. Em relação a origem do capital, o Brasil correspondia a 32,2\% dos investimentos, seguido da Argentina com 28,2\% e dos Estados Unidos, com 11\% dos investimentos externos diretos. Entre os países europeus, destaque para a Alemanha, com 5,8\% (LAMBERTI, 2011).

Contudo, embora tal processo tenha sido importante no âmbito do crescimento econômico, não seguiu na mesma perspectiva no que diz respeito ao social. Em 1980, $67 \%$ das famílias encontravam-se abaixo da linha da pobreza. Soma-se a isso a crise que afetou o país com o término das obras de Itaipu, além da queda dos preços da soja e do algodão.

A pesar de la larga duración de la dictadura, la misma no modificó estructuralmente el modelo económico del país, pues éste continuó siendo en 1989, tal como en la década del cincuenta, una economía abierta al comercio y al capital internacional sin mayor control estatal, dependiente de la demanda, los créditos y las inversiones extranjeras, vinculada a la economía mundial como proveedora de materias primas (incluyendo desde los ochenta, la electricidad para el Brasil y la Argentina), consumidora de bienes industriales, lugar de paso de mercancías hacia países vecinos (triangulación comercial), funcional al fortalecimiento de los circuitos industriales, fi nancieros y comerciales de países de mayor desarrollo, y con un débil y marginal sector industrial dentro del país (BORDA; MASI, 2003, p.88).

O processo inflacionário aumentou e a deterioração do consumo afetou a sociedade de uma forma geral. Em 1986 foi registrada a inflação mais alta dos últimos 33 anos, quando o índice de preço ao consumo chegou a 40,6\%. Como o país não teve um processo de industrialização por substituição de importações, a possibilidade encontrada foi a realização da reexportação de produtos importados, tanto em sua forma legal como ilegal.

Diante disso, a medida do consenso de Washington que mais amplamente se aplicou ao Paraguai, foi a abertuta externa e liberalização do comércio internacional. O país se abriu de forma unilateral, antes mesmo do Tratado de Assunção. Para Villagra (2015), essa abertura prematura está relacionada com uma estratégia adotada por alguns países industrializados para poder permear as economias fechadas do cone Sul, em especial o Brasil, através da triangulação comercial, ou 
reexportação. Este impulso ocorreu entre 1989 e 1995, visto que até 1985 as exportações do país equivaliam a $10 \%$ do PIB, alcançando em 1995, 48\%. Nas mesmas datas, as importações passaram de $14 \%$ para $50 \%$ do PIB, respectivamente (VILLAGRA, 2015).

Neste contexto, Ciudad del Este emergiu como o centro da triangulação comercial do país. Esta situação, segundo Villagra (2015), aprofundou a dependência econômica do Paraguai, visto o processo de exportação de produtos primários e a importação de produtos industrializados, somados aos de reexportação. Além disso, tem-se a escassa variedade de produtos exportados, bem como a reduzida geração de empregos. O autor nos mostra que na década de 1990 as exportações realizadas foram constítuidas por mais de $70 \%$ de produtos primários. A abertura comercial impossibilitou a industrialização no país, dada a inviabilidade de competir com a indústria internacional.

O comércio reexportador, bem como toda extensão do setor de comércio e serviços, passou, a partir da metade da década de 1990, a ter participação decrescente na economia. Isso se deu como consequência da crise brasileira, ou seja, da adoção do Plano Real atrelado a mudanças macroeconômicas, que colaboraram para a restrição do comércio fronteiriço.

Nesta discussão Masi (2001) mostra que, o Paraguai não contou com um processo de industrialização planejado ${ }^{7}$. O modelo econômico baseava-se na extração intensiva de recursos naturais e no dinamismo comercial de importação que se converteu em operações de triangulação comercial com os países vizinhos. $O$ autor acrescenta que, durante a década perdida para os demais países sul-americanos, o Paraguai não encontrava-se na mesma situação. Por isso, o país não adotou programas de ajuste, estabilidade e liberalização. Desta forma, a década de 1990 se expressou na composição do PIB com $54 \%$ do setor de serviços, $26 \%$ do agrícola e apenas $15 \%$ com indústria.

O censo industrial de 1997 apresentou 66\% dos estabelecimentos formados por pequenas empresas, com emprego de 7 a 19 trabalhadores, 28\% constituídas por médias indústrias (20 a 99 trabalhadores), enquanto as grandes unidades (mais de 100 empregados) representavam apenas $6 \%$ do total. A indústria apresenta uma participação média entre 15 e 17\% do PIB nas últimas décadas desde 1950.

É justamente no final da década de 1990 que o governo aposta em uma nova política para o impulsionamento da industrialização no país. A próxima parte aborda o processo de instauração da lei de maquila no Paraguai.

\section{MAQUILA: A NOVA DINÂMICA INDUSTRIAL NO PARAGUAI}

Para compreender o processo recente de industrialização no Paraguai é necessário regressar a origem do regime de maquila na América Latina, que inicialmente se deu no México ${ }^{8}$. Neste sentido verifica-se que, a partir das leis 806 e

\footnotetext{
${ }^{7}$ De acordo com Furtado (2007), duas fases de industrialização podem ser distinguidas. A primeira é marcada pelo estímulo a expansão das exportações, ou seja, a estrutura evolui de maneira inversa a que ocorre no perfil da demanda, sendo o aumento da produtividade acompanhada de uma simplificação na estrutura de oferta de origem interna e de diversificação na composição da demanda global. Na América do Sul o mercado se formou enquanto resultado da elevação da produtividade causada pela especialização externa sendo abastecido inicialmente por importações. A segunda fase diz respeito ao processo de substituição de importações e segundo o autor, só se concretizou nos países que já haviam passado pela primeira fase. Brasil, Argentina e México são exemplos dessa experiência, a qual também dependeu da ação estatal para a viabilização dos investimentos básicos. ${ }^{8}$ Além da forte presença no México, as maquilas estão empregadas na América Central e Caribe, como em El Salvador, Guatemala, Honduras, Nicarágua e Costa Rica. Estão diretamente relacionadas a acordos comerciais com os Estados Unidos.
} 
807 de 1966, as empresas norte-americanas foram incentivadas a exportarem matéria-prima sem taxação, desde que retornassem para o país com o produto acabado, ocasião em que seria taxado apenas sobre o valor agregado ao produto final. Desta forma, tornou-se vantajoso a instalação de tais indústrias em território mexicano.

Estas indústrias ficaram conhecidas como maquiladoras, nome em espanhol que tem sua origem no termo maquila, que corresponde a porção de farinha que 0 moleiro garante após moer o milho. "Os EUA fornecem o milho (matéria-prima), o México fica com um pouco da farinha (lucro sobre o câmbio de dólares para pesos e os salários dos funcionários) e a farinha (produto final) volta para os EUA, que normalmente é vendido para os trabalhadores da maquila que regularmente gastam parte do seu salário naquele país" (BAUMGRATZ, 2016, p.11).

Em 1965, a partir do Programa de Industrialização da Fronteira Norte, o governo mexicano criou uma política de fomento para as indústrias maquiladoras de exportação no norte do país. Com o passar dos anos, o governo estendeu o incentivo a todo território nacional; foi assim que teve início as maquilas mexicanas, formadas exclusivamente por indústrias norte-americanas.

Posteriormente, em 1994, foi criado o Tratado Norte-Americano de Livre Comércio - NAFTA, composto pelos Estados Unidos, México e Canadá. A partir do Nafta, a maquila ganhou força, favorecendo a importação de componentes e a exportação de produtos industrializados. Baumgratz (2016) explicita que, até os anos 2000 a força de trabalho nas maquilas foi ampliada em $110 \%$, no entanto, poucos estabelecimentos espandiram-se pelo território, concentrando-se nas áreas de fronteira. Para se ter noção desta realidade a autora aponta que, em 1995, 85\% dos trabalhadores das maquilas estavam empregados em um dos seis estados de fronteira.

Em relação ao crescimento deste modelo de indústria, os dados mostram que, em 1990 eram 1.500 estabelecimentos, passando para 3.700 em 2001. Sobre as exportações, em 1980 a maquila representava $10 \%$ do total exportado, passando para $45 \%$ em 2000. A partir de 2003, contudo, ocorre uma queda na maquila mexicana, quando cerca de 1.000 indústrias são fechadas. Para Villafañe (2004), trata-se da queda na atividade econômica norte-americana e da migração da produção para a China.

No que diz respeito a divisão do trabalho o autor aponta que, a mão-de-obra é formada majoritariamente por mulheres, jovens e indígenas, sem ou com baixa escolaridade. Para Baumgratz (2016, p.15) "[...] as maquiladoras pagam menos impostos que as empresas mexicanas, utilizam uma força de trabalho muito barata e possuem regulamentações ambientais que nunca são cumpridas".

Carrilo e Partida (2004) descrevem o processo de maquila a partir de 3 momentos. Como visto, a gênese ocorre com a inserção da maquila no México, e neste sentido os autores apontam que, o programa de industrialização via maquila teve início na década de 1960, com objetivo principal de geração de emprego. Esse período é marcado pela instalação de indústrias de baixo nível tecnológico, de montagem, com contratação de mão-de-obra barata e com baixo nível de qualificação.

O segundo momento é consequência da crise da década de 1980, quando ocorreu a reestruturação de diversos setores industriais pelo mundo, com a busca de novos mercados. Neste período destacam-se as indústrias automotiva e eletrônica, as quais exigiam mão-de-obra mais qualificada, alterando, mesmo que temporariamente, a divisão do trabalho nas maquilas mexicanas. Com maior capacidade produtiva, iniciou-se a terceirização das maquilas para fabricação de 
peças, manutenção e reparação. Soma-se a isso, a intensificação de capacitação técnica nas instituições de ensino. O terceiro momento abarca a década de 1990, caracterizado pela abertura comercial a nível mundial, pela reestruturação industrial de diversos setores, da difusão da tecnologia, entre outros elementos.

Enquanto no México discute-se a futura existência do regime de maquila frente as alterações na economia mundial, na América do Sul observa-se o sentido oposto, ou seja, a criação da lei de Maquila no Paraguai, permitindo, desde 2000, que indústrias estrangeiras instalem-se em seu território com uma tributação única de $1 \%$ sobre o valor agregado, sendo que parte deste valor ainda pode ser revertido para a indústria, além da importação livre de impostos e baixo custo de mão- de - obra, desde que no mínimo $90 \%$ dos produtos industrializados sejam exportados para o país de origem, dentro de dois anos.

A lei 1.064/97, promulgada pelo decreto 9.585/2000, no Paraguai, tem como órgão executor e regulador das indústrias maquiladoras, o Conselho Nacional das Indústrias Maquiladoras e Exportadoras - CNIME, pertencente ao Ministério de Indústria e Comércio do país e age em compasso com o Tratado do Mercosul. De acordo com Copetti Neto e Sousa (2016), a lei de Maquila paraguaia, ora criada com base no modelo mexicano, não pode ser confundida com a mesma, visto que não se estabelece, tampouco depende de investimento e da obrigatoriedade de exportação de produto industrializado para determinado país, como efetivamente ocorreu a partir da década de 1960 entre México e Estados Unidos. De acordo com Masi e Álvarez (2005, p.29), o marco jurídico contempla as seguintes formas de maquila:

i) Plantas Gemelas o Twin Plants: cuando el contrato de maquila se realiza entre una empresa extranjera con sucursal en el Paraguay 0 una empresa paraguaya con sucursal en el exterior, cuyas plantas son complementarias en la cadena de producción.

ii) Maquila Pura: cuando la actividad es realizada por una empresa maquiladora constituida para el efecto y que no tiene vínculos corporativos con la empresa contratante.

iii) Maquila por capacidad ociosa: cuando la actividad es efectuada por una empresa paraguaya ya constituida que aprovecha la capacidad ociosa de sus instalaciones para realizar operaciones de maquila.

iv) Subcontrato: cuando la empresa paraguaya ya constituida es subcontratada por una empresa maquiladora para realizar determinadas etapas del proceso de maquila.

v) Shelter o Programa de Albergue: cuando el contratante suministra todos los elementos necesarios para llevar acabo el proceso productivo. En este caso, los fabricantes del exterior establecen las especificaciones de los productos, supervisan el proceso y la calidad final.

Importante destacar que, apesar da implantação da lei, a mesma efetivou-se de fato, ganhando divulgação, após 2005, quando da intensificação da fiscalização na fronteira com o Brasil. De acordo com Cesar (2016), a comercialização de mercadorias representava uma das principais fontes de divisas do país, atrás apenas dos recursos gerados pela exportação de energia elétrica, soja e carne bovina, contribuindo, em média, com $0,7 \%$ de crescimento anual do PIB, no decorrer da última década. Atrelado a isso, o governo paraguaio apontou outros motivos para a implantação de uma legislação de atração de indústrias, como a necessidade de iniciar um processo de inserção do Paraguai no comércio internacional, aumentar a 
integração do país com outras economias regionais, fortalecer a economia nacional e geração de emprego (PARAGUAY, 2000).

No Paraguai existem apenas cinco impostos diferentes e eles incidem sobre a renda, o valor agregado (IVA), que é semelhante ao ICMS no Brasil, o imposto de importação, a contribuição social e uma taxa que incide especificamente sobre o consumo de combustível, bebidas e cigarros. Como contrapartida, o Paraguai exige como Regime de origem das importações, um perfil de composição regional, sendo ele $40 \%$ Mercosul e $60 \%$ extrazona. As empresas pertencentes a maquila pagam apenas um imposto, que corresponde a $1 \%$ do valor agregado.

No decorrer dos últimos anos, várias matérias publicadas na imprensa têm destacado o movimento de empresas brasileiras em direção ao Paraguai, a exemplo da matéria publicada no jornal O Estado de São Paulo ${ }^{9}$ no início de 2017, indicando que as empresas brasileiras têm se instalado no Paraguai em busca de menores custos, como a Riachuelo e companhias internacionais de autopeças, antes instaladas no Brasil. Em outra matéria, no jornal Folha de São Paulo ${ }^{10}$, é apontado que $69 \%$ das empresas instaladas no Paraguai sob o regime de maquila são brasileiras.

Nesta perspectiva o Ministério de Indústria e Comércio - MIC aponta que, os custos com mão-de-obra no Paraguai correspondem a $64,7 \%$ dos custos no Brasil ${ }^{11}$. Os diferenciais verificados estão relacionados principalmente com os encargos trabalhistas. Inserida nesta discussão, matéria publicada no jornal O Estado de São Paulo aponta que, no Paraguai o salário mínimo corresponde a US\$365 (R\$1.200 na data da publicação da mesma) ${ }^{12}$, sendo que os encargos trabalhistas correspondiam a $30 \%$, ou seja, inferior ao valor informado pelo MIC. No Brasil, por outro lado, esses encargos alcançam mais de $100 \%$ do salário.

Ainda sobre tais vantagens, o Jornal do Comércio ${ }^{13}$ aponta que, no Paraguai não há o pagamento de férias ou FGTS, além da jornada ser de 48 horas semanais e as férias de 12 dias úteis por ano. Neste conjunto, a Federação das Indústrias do Estado de São Paulo - FIESP, divulgou em 2013 o estudo "Comparativo dos Custos de Produção de Têxteis e Confecção no Brasil e no Paraguai", onde elaborou uma comparação a partir de quatro variáveis: insumo, mão-de-obra, manutenção e juros. O Paraguai apresentou vantagens nos quatro elementos: mão-de-obra $35,5 \%$ mais barata, energia elétrica, com tarifa do quilowatt/hora $63 \%$ menor, custos de produção $35 \%$ menores. Segundo César (2016), o Paraguai conta com algumas características estruturais, como um dos mais baixos níveis de capital humano e infraestrutura da América Latina, ausência de política industrial, carga tributária baixa, taxa elevada de subemprego.

La industrialización maquiladora es un nuevo patrón que responde a la reestructuración industrial trasnacional y es el eslabón más débil, marginal, de la cadena de producción y valor global. Reproduce el subdesarrollo y la dependencia, al reproducir los défi cits estructurales,

\footnotetext{
9 "Em busca de custos menores, empresas brasileiras abrem fábricas no Paraguai” (publicada em 2 de janeiro de 2017 no jornal “O Estado de São Paulo"). Disponível em https://economia.estadao.com.br/noticias/geral,em-busca-de-custos-menoresempresas-brasileiras-abrem-fabricas-no-paraguai,10000097591. Acesso em 15 de julho de 2018.

10 "Brasileiros abrem 7 de cada 10 indústrias do Paraguai" (publicada em 31 de dezembro de 2017 no jornal "Folha de São Paulo"). Disponível em https://www1.folha.uol.com.br/mercado/2017/12/1947163-brasileiros-abrem-7-de-cada-10-industriasdo-paraguai.shtml. Acesso em 03 de agosto de 2018.

${ }^{11}$ Dado disponível em https://goo.gl/3zvyD1. Acesso em 25 de outubro de 2018.

${ }^{12}$ De acordo com a legislação do Paraguai, em 2017 o salário mínimo era de 1.964 .507 guaranis no regime geral e G\$1.178.704 para trabalhadores/as domésticos/as. Porém, os altos índices de informalidade ocasionam a não efetivação da lei com uma parcela significativa da população que ganha menos que um salário mínimo.

13 "Paraguai tenta atrair indústrias brasileiras" (publicada em 30 de janeiro de 2017 no "Jornal do Comércio"). Disponível em https://www.jornaldocomercio.com/ conteudo/2017/01/economia/544089-paraguai-tenta-atrair-industrias-brasileiras.html. Acesso em 05 de novembro de 2018.
} 
profundizar la desarticulación de las cadenas industriales tradicionales y elevar la sobreexplotación de la fuerza de trabajo con nuevas modalidades de precarización laboral. Este patrón se vuelve predominante en la dinámica industrial, al abandonarse la política de sustitución de importaciones destinada al mercado interno; presenta altas tasas de crecimiento de su producción, fuerza de trabajo y sobre todo de sus exportaciones, ya que su producción está dirigida fundamentalmente al mercado externo (MORALES, 2009, p. 89).

No início do século XXI o Paraguai apresentou um expressivo crescimento econômico, inclusive após o golpe ${ }^{14}$. De acordo com o MIC, em 2017 existiam 124 maquilas instaladas no país, com predominânica de capital de países sul-americanos, como mostra a tabela 1 a seguir:

Tabela 1. Origem das maquilas: 2017

\begin{tabular}{c|c}
\hline Brasil & 71 \\
\hline Argetina & 25 \\
\hline Uruguai & 06 \\
\hline Holanda & 01 \\
\hline China & 01 \\
\hline EUA & 03 \\
\hline Alemanha & 01 \\
\hline Coparticipação & 01 \\
Mercosul/China & \\
\hline Coparticipação & 09 \\
Mercosul/ltália & \\
\hline Canadá & 01 \\
\hline Japão & 01 \\
\hline Coreia & 02 \\
\hline Não informado & 02 \\
\hline Total & 124 \\
\hline Fonte: MIC (2018)
\end{tabular}

Como apontado anteriormente, o Brasil é o país que mais investiu na transferência das indústrias para o Paraguai, contando em 2017 com 71 unidades, na sequência verifica-se a Argentina, com 25 estabelecimentos. A intensa presença de indústrias brasileiras e argentinas, entre os aspectos já mencionados, diz respeito a proximidade física dos países e a infraestrutura de transporte disponível. Também foram contabilizadas indústrias em coparticipação Mercosul/Itália e Mercosul/China, as quais totalizaram nove e uma indústria, respectivamente. Uruguai conta com seis indústrias maquiladoras no Paraguai, Estados Unidos conta com três unidades, Coreia possui duas unidades. Países como Holanda, China, Alemanha, Canadá e Japão possuem uma indústria cada.

Assunção e suas proximidades e o departamento de Alto Paraná são as áreas que melhor se desenvolveram a partir da maquila. Isso se deu pela presença de infraestrutura e pela disponibilidade de mão-de-obra. Soma-se a isso o fato de Alto Paraná localizar-se na fronteira com o Brasil, facilitando o transporte das mercadorias. Neste sentido cabe mencionar que, em 2015 Alto Paraná foi responsável por 25\% das exportações do Paraguai. A tabela 2 mostra os dados referentes a localização das indústrias de acordo com os departamentos.

\footnotetext{
${ }^{14}$ Para aprofundamento a respeito do golpe ocorrido no Paraguai, ler Santos (2013).
} 
Tabela 2. Localização das maquilas por departamento: 2017

\begin{tabular}{|c|c|}
\hline Alto Paraná & 55 \\
\hline Amambay & 10 \\
\hline Caaguazu & 02 \\
\hline Caazapa & 01 \\
\hline Canindeyu & 03 \\
\hline Capital & 07 \\
\hline Central & 42 \\
\hline Guaira & 01 \\
\hline Itapuá & 01 \\
\hline Ñeembucu & 01 \\
\hline Presidente Hayes & 01 \\
\hline Total & 124 \\
\hline
\end{tabular}

Os dados confirmam que, o departamento de Alto Paraná é o que mais abriga indústrias via regime de maquila, seguido de Assunção e do Centro do país. No início de 2017 as exportações via maquila alcançaram US\$27.841.515, ou seja, aumento de $29 \%$ em relação ao mesmo período de 2016. De acordo com o CNIME, em fevereiro de 2017 o setor que mais exportou foi o de autopeças, com $48,1 \%$, seguido por confecção e têxtil com $20 \%$. Os destinos são majoritariamente dentro do Mercosul, no entanto, também foram registradas exportações para Tailândia, Estados Unidos, França e Vietnã.

A Estrela, por exemplo, possui 3 indústrias no Brasil e a unidade no Paraguai foi inaugurada em fevereiro de 2017. A mesma está localizada em Hernandarias e possui $6 \mathrm{mil} \mathrm{m}^{2}$, com vistas de ampliação para $13 \mathrm{mil} \mathrm{m}^{2}$. Atualmente emprega 100 pessoas, devendo empregar 200 até 2022. De acordo com o presidente da unidade paraguaia (2018), a ideia é que o Paraguai substitua a China no que diz respeito a novos negócios. Acrescenta que a estratégia é produzir no Paraguai a parte que era importada da China, onde inclusive, a empresa encerrou as atividades de sua unidade. Além disso, o presidente afirma que, o nível de importações a partir de 2017 pode acarretar em queda no número de contratações de trabalhadores no Brasil, tendo em vista que, em 2016 a empresa empregava cerca de 2 mil trabalhadores e que em 2017 esse número caiu para 1.500.

Dados mais atuais mostram que, em 2018 Alto Paraná já conta com 101 indústrias, além de 52 projetos aprovados, onde $70 \%$ são investidores brasileiros (LEITE, 2018). De acordo com o Ministro da Indústria e Comércio, Gustavo Leite (2018), já foram realizados investimentos na ordem de US\$185 milhões em infraestrutura voltada para a captação de indústrias. Além disso, US\$150 milhões foram exportados apenas no mês de março de 2018. Toda essa dinâmica possibilitou a criação de 4.500 empregos diretos no departamento de Alto Paraná.

O censo nacional econômico de 2011 contabilizou 24.704 indústrias em território paraguaio, sendo $88,5 \%$ compostos por pequenas unidades (DEEGEC, 2011). Verifica-se que o número de indústrias através do regime de maquila é bem reduzido em comparação ao número total, contudo, por tratar-se de uma dinâmica em pleno processo, muita coisa ainda está por ocorrer. Diante disso, a análise acerca da industrialização do Paraguai através do regime de maquila também é uma análise ainda parcial, visto que o mesmo encontra-se no auge de sua realização. Por outro lado, verifica-se que os impactos do movimento descrito nas indústrias, majoritariamente brasileiras, pode sugerir um cenário favorável.

Com efeito, para os industriais trata-se de uma oportunidade de produzir com menores custos de mão-de-obra e de energia, com o pagamento de menos tributos e 
com algumas facilidades adicionais. Esse quadro sugere, a princípio, impactos positivos para as indústrias. No entanto, é necessário considerar que, para a economia brasileira pode haver impactos negativos resultantes do movimento de empresas para outro país. Com o passar do tempo, esse movimento pode ser ampliado por fornecedores locais que possivelmente se instalarão nas proximidades de seus mercados consumidores. Isso significa menor geração de empregos no Brasil e menores níveis de arrecadação, sem aprofundar na questão da precarização do trabalho no Paraguai, tema amplo a ser discutido e analisado em outra oportunidade.

\section{CONSIDERAÇÕES FINAIS}

O Paraguai, apesar de ter contado com um breve momento em que a industrialização esteve no cerne das políticas governamentais, historicamente teve sua economia ligada aos setores primário e terciário. Trata-se de uma formação socioespacial da grande propriedade, com relações de trabalho efetivamente precárias e informais.

Atrelado a isso, tem-se a ausência de instituições educacionais, políticas e sindicais, visto a falta de novos agentes sociais como força de representatividade política, mesmo depois do término do regime militar. O Paraguai passou por um processo baseado na expansão da economia terciária, com predomínio do trabalho informal. Essa informalidade está estritamente ligada com a pobreza e exclusão social. Tal realidade tem relação com a escassa capitalização das empresas, com a falta de financiamento creditício e inexistência de políticas de desenvolvimento industrial.

A criação da lei de maquila no país, apesar de apresentar algumas mudanças, especialmente em relação a criação de postos de trabalho, na prática não altera a formação social e econômica do país, especialmente se considerar os elementos que fazem com que as indústrias, majoritariamente brasileiras, se transfiram para 0 Paraguai. Com a ausência de impostos e com uma mão-de-obra desqualificada, pouco remunerada e sem benefícios, o desenvolvimento industrial e social seguirá a linha do que a história tem mostrado no decorrer dos mais de dois séculos, aqui brevemente abordados.

\section{REFERÊNCIAS BIBLIOGRÁFICAS}

BANDEIRA, L, A, M. O Expansionismo Brasileiro e a Formação dos Estados na Bacia do Prata - Da colonização à guerra da tríplice aliança. Brasília: Editora da UnB e Editora Revan, 1985.

BAUMGRATZ, D. Regime de Maquila e suas implicações para os trabalhadores na fronteira com o México: perspectivas para o modelo adotado no Paraguai. Semana Acadêmica de Relações Internacionais e Integração. Anais..., Foz do Iguaçu, 2016.

BETHELL, L. O imperialismo britânico e a Guerra do Paraguai. Estudos Avançados, v.9, n.24, São Paulo, mai/ago, 1995.

BORDA, D. Auge y Crisis de un Modelo Económico: el Caso Paraguayo. Asunción: Universidad Católica, 1994. 
BOURSCHEID, J, I, J. República do Paraguai: a pátria do Marechal destruida pelo consenso liberal-civilizador. Cadernos de Relações Internacionais, v.7, n.11, Rio de janeiro, 2014.

CARRILLO, J; PARTIDA, R. La Industria Maquiladora Mexicana: Aprendizaje Tecnológico, Impacto Regional y Entornos Institucionales. 2004. Disponível em: https://www.colef.mx/jorgecarrillo/wp-content/uploads/2012/04/PU288.pdf . Acesso em: 05 jun. 2018.

CASADO, J, H, M; PAIAS, K, R, M; TEODORO, G, R. A Lei da Maquila como instrumento catalisador das relações internacionais entre Brasil e Paraguai. Revista Ciências Gerênciais, v.35, n.35, Londrina, 2018.

CANESE, R. A recuperação da soberania hidrelétrica do Paraguai. In: CODAS, G. (org.). $\mathbf{O}$ direito do Paraguai à soberania. São Paulo: Expressão Popular, 2008.

CÉSAR, G, R, C de. Integração Produtiva Paraguai-Brasil: novos passos no relacionamento Bilateral, Boletim de Economia e Política Internacional, n.22, Brasília, Jan/Abr, 2016.

COPETTI NETO, A; SOUZA, J C. Lei de Maquila: uma alternativa ao desenvolvimento regional. Santa Maria, RS: Emporio do Direito, 2016.

FABIO, Y V. La maquila em Paraguay, Población y desarrollo: decênio internacional de las poblaciones indígenas del mundo, San Lorenzo, Paraguay, Año XIV, n.2, p. 32-45, jun. 2004.

FIESP - FEDERAÇÃO DAS INDÚSTRIAS DO ESTADO DE SÃO PAULO. Raio $\mathbf{X}$ do comércio exterior brasileiro 2015. São Paulo: Fiesp, 2016. Disponível em: https://sitefiespstorage.blob.core.windows.net/ . Acesso em: 29 set. 2018.

FIGUEREDO, O, A, T; FILIPPI, E, E. O Paraguai e sua inserção econômica na globalização: o caso da soja. Sociedade Brasileira de Economia e Sociologia Rural, Anais... Ribeirão Preto, jul, 2005.

FURTADO, C. A Economia Latino Americana. São Paulo: Cia das Letras, 2007.

LAMBERTI, E. Regulação e reprodução do sistema socioeconômico: análise da trajetória do desenvlvimento paraguaio. 2011. Tese (Doutorado em economia). Universidade Federal do Rio Grande do Sul, 2011.

LENIN, V, I. Imperialismo: etapa superior do capitalismo. Campinas: FE/UNICAMP, 2011.

MACIEL, R, E, A. A maquila no Paraguai: modelo produtivo e integração no início do século XXI, 2017. (dissertação de mestrado em Integração Contemporânea). Universidade Federal da Integração Latino-Americana, Foz do Iguaçu, 2017. 
MASI, F. Ups and downs of Paraguayan trade policy in the 90s. In: BOUZAS, R. (Org.). Domestic determinants of national trade strategies: a comparative analysis of Mercosur countries, Mexico and Chile. Paris: Obreal/Eularo, 2001.

MASI, F; ÁLVAREZ, E. Políticas Nacionales de Competitividad en el Paraguay y su Impacto en la Profundización del MERCOSUR. In: Política de Promoción de las Exportaciones. Santiago de Chile: Comisión Económica para América Latina y el Caribe (CEPAL), Chile, 2005.

MOLINIER, L. Paraguai: el retorno neoliberal, avances y tensiones de un proyecto más dependiente y desigual. In: PUELLO-SOCARRÁS et al. Neoliberalismo en América Latina. Asunción: CLACSO, 2015.

MORALES, J. Crisis, inversión extranjera directa y nuevo patrón manufactureroexportador". In: Economía mundial, corporaciones transnacionales y economías nacionales. Buenos Aires: CLACSO, 2009.

ODDONE, H. Cuatro hitos históricos de la dinâmica poblacional y territorial de Paraguay Independiente. $4^{\circ}$ Congreso Paraguayo de Población, Anais... Assuncion, 2011.

PASTORE, C. La lucha por la tierra en el Paraguay. Montevidéu: Antequera, 1972.

QUINTIN, R. Los sin tierra en Paraguay: conflictos agrarios y movimiento campesino. CLACSO, Buenos Aires, 2003.

SALES, T, R. Um Conflito Anunciado: o cenário sul - americano as vésperas da Guerra do Paraguai. XII Encontro Regional de História ANPUH. Anais... Rio de Janeiro, 2006.

SANTOS, F, L, B dos. A deposição de Lugo e os limites da democracia na América Latina. Cadernos Prolam, USP, a.12, v.1, São Paulo, 2013.

VILLAFAÑE, Victor Lopez. La industrialización de la frontera norte de México y los modelos exportadores Asiáticos. Comercio Exterior, v. 54, n.8, Talphan, 2004.

VILLAGRA, L, R. Proceso histórico de la economía paraguaya. Asunción: Secretaría Nacional de Cultura, 2015. 